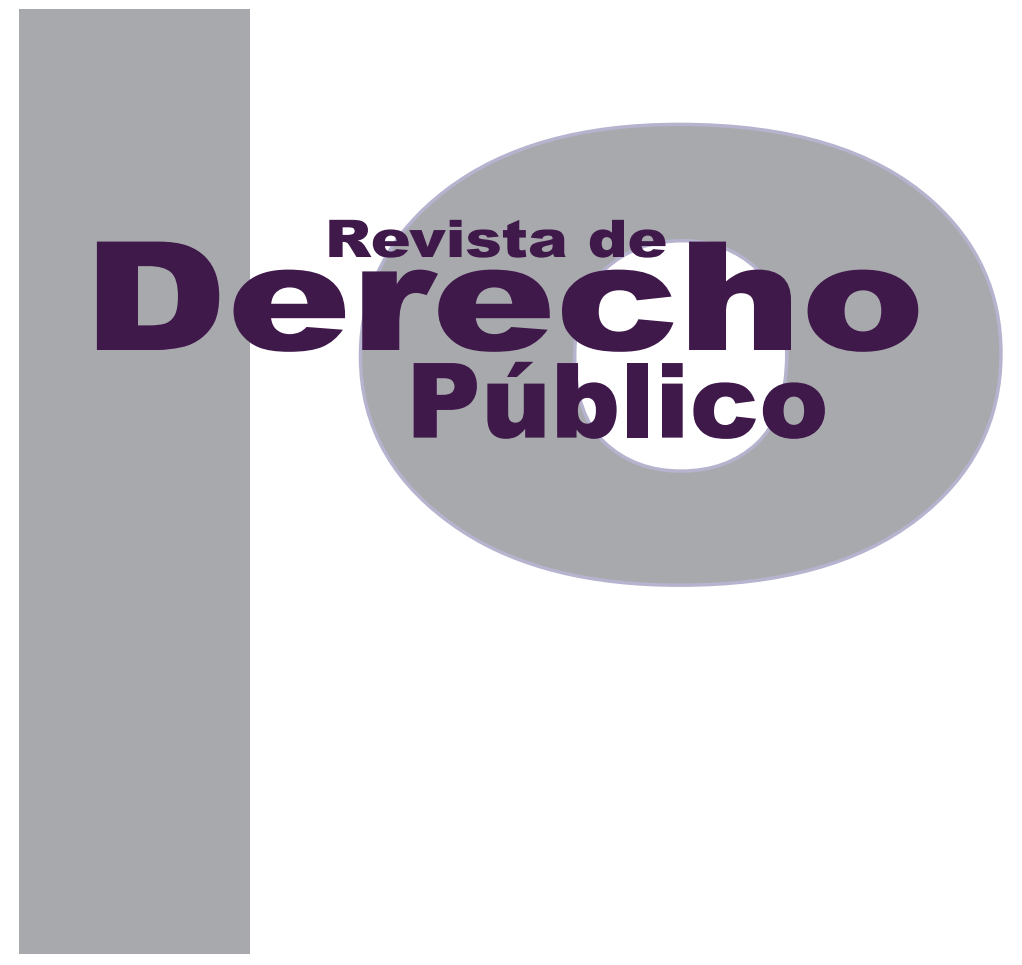

EL ESTADO MEXICANO, GARANTE DE LA EFICAZ REPARACIÓN DEL DAÑO EN NIÑAS, NIÑOS Y ADOLESCENTES VÍCTIMAS DE DELITOS SEXUALES

\author{
José Christian PÉRez Flores
}

Artículo de reflexión

DOI: http://dx.doi.org/10.15425/redepub.33.2014.09

Universidad de los Andes

Facultad de Derecho

Revista de Derecho Público N. ${ }^{\circ} 33$

Julio - Diciembre de 2014. ISSN 1909-7778 


\title{
El Estado mexicano, garante de la eficaz reparación del daño en niñas, niños y adolescentes víctimas de delitos sexuales
}

\section{Resumen}

Dentro de las consecuencias jurídicas derivadas de la comisión de un delito está la condena a la reparación del daño; el presente trabajo se centra en la reparación del daño moral en el caso de delitos de carácter sexual cometidos en contra de niñas, niños y adolescentes. El objetivo principal es brindar al lector un panorama amplio de los aspectos que comprende dicha medida, pero particularmente, establecer las obligaciones del Estado como garante de que esa reparación del daño sea debidamente aplicada en atención a sus fines. La metodología empleada comprende un análisis monográfico interpretativo de instrumentos doctrinales, legales y fuentes de información diversa, cuya unión justifica la argumentación expuesta. En conclusión, se establece que corresponde al Estado velar porque la reparación del daño moral en los casos señalados, sea aplicada de manera correcta en favor de las víctimas directas.

Palabras clave: reparación del daño; daño moral; niñas, niños y adolescentes; delito sexual, condena, sentencia judicial, derechos humanos.

\section{The Mexican State, guarantor of effective reparation in children and adolescent victims of sexual offenses}

\begin{abstract}
Within the legal consequences of committing a crime is sentenced to repair the damage; this paper focuses on reparation for moral damages in the case of sexual offenses committed against children and adolescents. The main objective is to provide the reader with a comprehensive overview of aspects comprising the measure, but particularly, establish state obligations as guarantor of reparation that is properly applied in attention to its purposes. The methodology includes an interpretive case study analysis of doctrinal, legal and diverse sources of information instruments, whose union justify the argument employed. In conclusion it is stated that the State must ensure that reparation for moral damages in the cases mentioned, is applied correctly in favor of the direct victims.
\end{abstract}

Keywords: repair damages, moral damages, children and adolescents, sexual offense, conviction, judgment, human rights.

\section{O Estado mexicano, garantia da eficaz reparação do dano em meninas, meninos e adoles- centes vítimas de delitos sexuais}

\section{Resumo}

Dentro das consequências jurídicas derivadas da comissão de um delito está a condena à reparação do dano; o presente trabalho está centrado na reparação do dano moral no caso de delitos de carácter sexual cometidos contra meninas, meninos e adolescentes. O principal objetivo é brindar ao leitor um panorama amplo dos aspectos que compreende dita medida, mais particularmente, estabelecer as obrigações do Estado como garantia de que essa reparação do dano seja devidamente aplicada em atenção a seus fins. A metodologia empregada compreende uma análise monográfica interpretativa de instrumentos doutrinais, legais e fontes de informação diversa, cuja união justifica a argumentação exposta. Em conclusão, é estabelecido que corresponde ao Estado velar para que a reparação do dano moral nos casos expostos, seja aplicada de maneira correta a favor das vítimas diretas.

Palavras-chave: reparação do dano; dano moral; meninas, meninos e adolescentes; delito sexual, condena, sentença judicial, direitos humanos. 


\title{
El Estado mexicano, garante de la eficaz reparación del daño en niñas, niños y adolescentes víctimas de delitos sexuales*
}

\author{
José Christian Pérez Flores**
}

\section{SUMARIO}

Introducción - I. LA NECESIDAD DE LA REPARACIÓN DEL DAÑO MORAL COMO CONSECUENCIA DE DELITOS SEXUALES A. El daño moral, un acercamiento a su definición en el ámbito legal - B. Repercusiones del daño moral en niñas, niños y adolescentes víctimas de delitos sexuales - II. NIÑAS, NIÑOS Y ADOLESCENTES. SUS DERECHOS COMO VÍCTIMAS DEL DELITO - A. Fundamentos de los derechos de niñas, niños y adolescentes víctimas de delitos sexuales - B. Marco legal nacional e internacional - III. EL ESTADO COMO GARANTE DE LA CORRECTA APLICACIÓN DE LA REPARACIÓN DEL DAÑO MORAL. SU JUSTIFICACIÓN - A. De las obligaciones del Estado - B. El derecho a recibir atención con independencia al derecho a la eficaz aplicación de la reparación del daño moral - IV. CONCLUSIONES - Referencias.

* Cómo citar este artículo: Pérez Flores, J. C. (Diciembre, 2014). El Estado mexicano, garante de la eficaz reparación del daño en niñas, niños y adolescentes víctimas de delitos sexuales. Revista de Derecho Público, 33. Universidad de los Andes (Colombia).

** Licenciado en Derecho por la Universidad Autónoma de Yucatán; cursó la Maestría en el Sistema de Justicia Penal Acusatorio y Litigación Oral en la Universidad Modelo campus Mérida; docente certificado por evaluación de la Secretaría Técnica de Coordinación para la Implementación del Sistema de Justicia Penal Acusatorio (SETEC) en los temas de Sistema Penal Acusatorio (proceso 2013) y Derechos Humanos (proceso 2014); actualmente se desempeña como Secretario de Estudio y Cuenta en la Ponencia Segunda de la Sala Colegiada Penal del Tribunal Superior de Justicia del Estado de Yucatán; docente de diversos cursos en temas relacionados con el sistema acusatorio, derechos humanos y debido proceso; catedrático de la Universidad Mesoamericana de San Agustín y en la Facultad de Derecho de la Universidad Marista de Mérida; autor de diversos ensayos académicos y trabajos de investigación. Correo: jcpfmaristaderecho@gmail.com 
Introducción

Sin lugar a dudas, uno de los principales fines del derecho penal, y en sí de los procesos penales, es la reparación del daño, ${ }^{1}$ entendiéndose como tal, la reintegración de los daños sufridos por la víctima u ofendido como consecuencia de la comisión de un delito, o como señala Julio A. Hernández Pliego, en su libro Programa de Derecho Procesal Penal "es el derecho del ofendido por el delito o de sus causahabientes, para que se les paguen los daños y se les indemnicen los perjuicios ocasionados con motivo del delito" (2006, pp. 335 y 336).

Para ello, jueces y tribunales deben estudiar de manera pormenorizada en cada caso sometido a su arbitrio y jurisdicción, la procedencia, alcances y cuantía de la imposición de tal medida, como parte de una sentencia condenatoria, pero ¿será suficiente condenar a una persona al pago de la reparación del daño, para que en todos los casos se pueda hablar de una verdadera aplicación de justicia?

1 La reparación del daño se encuentra contemplada en la Constitución Política mexicana, como un principio general del proceso penal, al disponer en el artículo 20, apartado A - De los principios generales-en la fracción I: "El proceso penal tendrá por objeto el esclarecimiento de los hechos, proteger al inocente, procurar que el culpable no quede impune y que los daños causados por el delito se reparen" (cursivas añadidas). Principio que si bien hace referencia al Sistema Penal Acusatorio y Oral, no debe perderse de vista que de igual forma se encontraba contenido en el texto constitucional mexicano (todavía vigente para los lugares en los que aún opera el sistema tradicional mixto, y para aquellos procesos iniciados con anterioridad a la reforma), previo a la reforma del 18 de junio de 2008, pues en el mismo artículo 20, apartado B - [De los derechos] De la víctima o del ofendido- en la fracción IV se disponía: "Que se le repare el daño. En los casos en que sea procedente, el Ministerio Público estará obligado a solicitar la reparación del daño y el juzgador no podrá absolver al sentenciado de dicha reparación si ha emitido una sentencia condenatoria. La ley fijará procedimientos ágiles para ejecutar las sentencias en materia de reparación del daño".
Al respecto de dicho tema han surgido diversas tesis y corrientes, como la justicia restaurativa, en la que se presupone una reparación del daño integral, en aras a restablecer no solo la disociación sustancial acarreada con la afectación al bien jurídico protegido que ha sido vulnerado, sino, además, una rearmonización social (por llamarlo de alguna forma) de todo lo inherente a la comisión del delito, tanto de la víctima como del victimario, y de las personas involucradas en el hecho, como familiares, testigos y terceros circundantes, ello con el fin de alcanzar la paz social (Meza, 2004, p.16).

Ahora bien, las niñas, niños y adolescentes resultan ser un sector sumamente vulnerable de la sociedad, cuyo derecho y protección a una eficaz reparación del daño no debe dejarse a la deriva y al simple cumplimiento por parte del sentenciado ante un tribunal de ejecución, sino que, en mi opinión y basado en el presente trabajo, su aplicación debe estar bajo la vigilancia de los órganos estatales, ante la posibilidad de que los medios para alcanzar la reparación del daño no sean destinados para una verdadera función restaurativa.

El derecho a la reparación del daño que tienen niñas, niños y adolescentes víctimas de delitos de carácter sexual ha sido un tema emergente, defendido e impulsado por diversas instituciones nacionales y transnacionales, así como por organismos no gubernamentales, y abordado desde distintos puntos de vista; lo cierto es que se ha soslayado la necesidad de que sea el mismo Estado, a través de los mecanismos con los que cuenta en sus diferentes 
esferas de Gobierno, quien se encargue de velar por el irrestricto destino de tal consecuencia jurídica del delito, en favor de quienes verdaderamente lo requieren.

No debe perderse de vista que ante un proceso de índole judicial, las niñas, niños y adolescentes deben estar representados, ya sea por un familiar, según el orden de prelación que la ley dispone en cada entidad federativa para ese efecto (normalmente los ascendientes), ${ }^{2} \mathrm{o}$ bien por un ente estatal que deberá vigilar y velar por el respeto de los derechos humanos de sus representados (Procuradurías de la Defensa del Menor y la Familiar, por ejemplo).

En ese sentido, y desde mi punto de vista, se corre el riesgo de que no se satisfagan las necesidades primordiales y predominantes para lograr reparar los daños causados con la comisión de un delito, sobre todo de carácter sexual, pues ello requiere de una aplicación enfática encaminada a tal efecto, y que al dejarse en el libre manejo de los representantes de las niñas, niños $y$ adolescentes puede no arribar a tal finalidad.

Por ejemplo, supongamos que un delito sexual fue cometido en contra de un niño perteneciente a una familia de escasos recursos; supongamos que ante la denuncia penal, se sigue un proceso judicial, se condena al responsable a las diversas penas, entre ellas la reparación del

2 Por ejemplo, el artículo 115 del Código Federal de Procedimientos Penales, en México, dispone: cuando el ofendido sea menor de edad, pero mayor de dieciséis años, podrá querellarse por sí mismo o por quien esté legitimado para ello. Tratándose de menores de esta edad o de otros incapaces, la querella se presentará por quienes ejerzan la patria potestad o la tutela. daño moral, y dicho sentenciado cumple con esa pena al comparecer ante una autoridad judicial de ejecución y hacer entrega de la cantidad que le fue fijada, misma que será entregada al representante legal del niño, que podríamos suponer, como en la mayoría de los casos, es la madre de la víctima; luego, dicha reparación del daño moral ¿realmente será aplicada para tratar de remediar los daños morales que haya sufrido el directo agraviado? En la mayoría de los casos la respuesta a dicha pregunta es negativa, pues los recursos emergentes de la condena a la reparación del daño moral son utilizados en beneficio de otros intereses, ajenos a la víctima de la comisión del delito, y finalmente generan, lo que yo llamo, una impunidad unilateral, pues si bien el infractor de la norma ha recibido una pena y ha cumplido con esta, la víctima no ha sido resarcida del daño causado.

En el presente trabajo, como he dejado ver, expondré lo concerniente a la reparación del daño moral, pues a mi parecer tal rubro resulta de suma trascendencia como una restitución necesaria y urgente de corto, mediano y largo plazo para las víctimas, tratándose de los daños ocasionados por delitos de carácter sexual cometidos en contra de niñas, niños y adolescentes, y sus afectaciones psicológicas y sociales, así como la naturaleza del Estado en cuanto instrumento garante de la aplicación eficaz de tal derecho humano.

Abordar dicha temática me representa una excelente oportunidad para transmitir mi incertidumbre y preocupación sobre este tema, pero además, y de ser posible, hacer que esa incer- 
tidumbre vaya un poco más allá, despertando en otros la misma preocupación de modo que sirva como impulso para la búsqueda de una solución, pues hasta ahora el Estado ha mostrado desinterés por vigilar que los recursos derivados de la pena referente a la reparación del daño moral sean efectivamente aplicados en favor de quienes realmente lo necesitan, lo cual representa un obstáculo que enfrentan las niñas, niños y adolescentes para acceder a la justicia.

La selección de tal temática no ha surgido del vacío; es resultado de lo que en mi desempeño profesional he podido apreciar en los procesos iniciados con motivo de delitos sexuales cometidos contra niñas, niños y adolescentes, y lo que he observado, respecto a la finalización de tales procesos.

Con la esperanza de clarificar mis objetivos, trataré de ser preciso en los conceptos que estimo necesario mencionar, en la exposición concreta de la problemática abordada y en las soluciones que a mi parecer resultan ser una posible vía para tratar de abatir el problema, basado en la razón, la doctrina, la jurisprudencia y las leyes en vigor.

\section{LA NECESIDAD DE LA REPARACIÓN DEL DAÑO MORAL COMO CONSECUENCIA DE DELITOS} SEXUALES

Aun cuando en el presente trabajo no pretendo establecer o enfatizar la importancia de la reparación del daño moral, que se origina con motivo de la comisión de un delito de carácter sexual perpetrado en contra de niñas, niños y adolescentes, pues tal cuestión se encuentra bien definida y formada, lo que sí estimo de vital importancia es conceptualizar el porqué de esa necesidad, lo que llevará a clarificar el objetivo del ensayo mediante el adentramiento de la problemática planteada, para lo cual resultará necesario, en primer término, hacer referencia a los rubros que se relacionan con el tema principal, seguido de un breve análisis de las consecuencias psicológicas, morales, sociales y personales, que los delitos de esa índole ocasionan.

\section{A. El daño moral, un acercamiento a su definición en el ámbito legal}

No es posible emitir o hacer referencia a una definición concreta-universal de lo que significa la expresión "daño moral", sin embargo, la doctrina, la ley, la jurisprudencia, la experiencia y la razón, en conjunto nos llevan hacia una conceptualización útil para jueces y tribunales al momento de considerar necesaria una restitución para tal agravio y emitir una sentencia condenatoria, así como para aquellos que pretendan exigirla frente a los tribunales.

Partamos por la definición de daño que Alicia Elena Pérez Duarte y Noroña proporciona en su artículo El daño moral, definiéndolo como “todo menoscabo o pérdida que una persona sufre en su persona o sus bienes producido por un agente externo" (1985, p. 626); para efectos del presente trabajo y por la temática abordada, interesa aquí la afectación que sufre la perso- 
na, producida por un agente externo, pues en definitiva el daño moral no es parte integrante de los bienes, sino algo intangible y difícilmente cuantificable en lo económico; por ello la doctrina coincide en que el daño se divide en patrimonial o material y no patrimonial o moral.

Apegándonos a la definición concluyente proporcionada por la autora ya citada, podemos referirnos al daño moral "como aquel detrimento no patrimonial, afectivo, que sufre una persona por la conducta ilícita de otro" (Pérez Duarte, 1985, pp. 627 y 628$)$.

Otras corrientes prefieren la denominación agravio moral sobre la de daño moral, por considerar que el daño provee una noción material, económica, patrimonial, y el agravio en cambio, no es propio de las cosas materiales. (Enciclopedia Jurídica omeBA, s.f. pp. 604 y 605). Sin embargo, y por la referencia al ámbito legal en México, se hace alusión al término ya empleado.

El Código Penal Federal de México, al referirse a la reparación del daño, establece en el artículo 30, fracción II, que esta comprenderá

la indemnización del daño material y moral causado, incluyendo la atención médica y psicológica, de los servicios sociales y de rehabilitación o tratamientos curativos necesarios para la recuperación de la salud, que hubiere requerido o requiera la víctima, como consecuencia del delito. En los casos de delitos contra el libre desarrollo de la personalidad, la libertad y el normal desarrollo psicosexual y en su salud mental, así como de violencia familiar, además comprenderá el pago de los tratamientos psi- coterapéuticos que sean necesarios para la víctima.

De donde se aprecia que aun cuando en dicha codificación no se establece en sí, qué se entiende por daño moral, sí es posible abstraer lo que el legislador plasmó como las consecuencias derivadas de la comisión de los delitos que dan lugar a un daño moral, mediante la identificación de lo que se debe reparar en ese caso.

Por su parte, el artículo 1916 del Código Civil Federal de México establece que por daño moral se entiende:

la afectación que una persona sufre en sus sentimientos, afectos, creencias, decoro, honor, reputación, vida privada, configuración y aspectos físicos, o bien en la consideración que de sí misma tienen los demás. Se presumirá que hubo daño moral cuando se vulnere o menoscabe ilegítimamente la libertad o la integridad física o psíquica de las personas.

La misma Codificación Civil en cita establece que la reparación del daño moral se efectuará mediante una indemnización en dinero, cuyo monto lo determinará el juez, tomando en cuenta los derechos lesionados, el grado de responsabilidad, la situación económica del responsable, y la de la víctima, así como las demás circunstancias del caso.

Ahora bien, en el ámbito del Poder Judicial de la Federación, el Tercer Tribunal Colegiado en Materia Civil del Primer Circuito estableció la definición de daño moral, en la tesis jurisprudencial número I.3o.C. J/71, relativa a la Décima Época, 
cuyo rubro y texto a continuación se transcriben de manera literal:

DAÑO MORAL. ES LA ALTERACIÓN PROFUNDA QUE SUFRE UNA PERSONA EN SUS SENTIMIENTOS, AFECTOS, CREENCIAS, DECORO, HONOR, REPUTACIÓN, VIDA PRIVADA, CONFIGURACIÓN Y ASPECTOS FÍSICOS, O BIEN, EN LA CONSIDERACIÓN QUE DE Sí MISMA TIENEN LOS DEMÁS, PRODUCIDA POR HECHO ILÍCITO. EI derecho romano, durante sus últimas etapas, admitió la necesidad de resarcir los daños morales, inspirado en un principio de buena fe, y en la actitud que debe observar todo hombre de respeto a la integridad moral de los demás; consagró este derecho el principio de que junto a los bienes materiales de la vida, objeto de protección jurídica, existen otros inherentes al individuo mismo, que deben también ser tutelados y protegidos, aun cuando no sean bienes materiales. En México, la finalidad del legislador, al reformar los artículos 1916 y adicionar el 1916 Bis del Código Civil para el Distrito Federal, mediante decreto publicado en el Diario Oficial de la Federación el treinta y uno de diciembre de mil novecientos ochenta y dos, y posteriormente modificar los párrafos primero y segundo del artículo 1916, consistió en hacer responsable civilmente a todo aquel que, incluso, ejerce su derecho de expresión a través de un medio de información masivo, afecte a sus semejantes, atacando la moral, la paz pública, el derecho de terceros, o bien, provoque algún delito o perturbe el orden público, que son precisamente los límites que claramente previenen los artículos 6o. y 7o. de la Constitución General de la República. Así, de acuerdo con el texto positivo, por daño moral debe entenderse la alteración profunda que una persona sufre en sus sentimientos, afectos, creencias, decoro, honor, reputación, vida privada, configuración y aspectos físicos, o bien, en la con- sideración que de sí misma tienen los demás, producida por un hecho ilícito. Por tanto, para que se produzca el daño moral se requiere: a) que exista afectación en la persona, de cualesquiera de los bienes que tutela el artículo 1916 del Código Civil; b) que esa afectación sea consecuencia de un hecho ilícito; y, c) que haya una relación de causa-efecto entre ambos acontecimientos (Suprema Corte de Justicia de la Nación, 2012, p. 4036).

En cuanto a la obligación de la reparación del daño, existen diversos mecanismos internacionales que se han encargado de establecerla, como por ejemplo, la Declaración sobre los Principios Fundamentales de Justicia para las Víctimas de Delitos y del Abuso del Poder, ${ }^{3}$ la cual determina en su artículo 4, que las víctimas tendrán derecho al acceso a los mecanismos de la justicia y a una pronta reparación del daño que hayan sufrido, según lo dispuesto en la legislación nacional; en el artículo 8 establece la obligación de los delincuentes o terceros responsables al resarcimiento equitativo de los daños producidos por su conducta, comprendiendo la devolución de los bienes, o el pago por los daños o pérdidas sufridos, el reembolso de los gastos realizados como consecuencia de la victimización, la prestación de servicios o la restitución de derechos.

De las citas anteriores podemos concluir que el daño moral es aquel que, derivado de la comisión de un hecho delictivo, produce un menoscabo en las condiciones personales intangibles

3 Adoptada por la Organización de las Naciones Unidas, el 29 de noviembre de 1985. 
de la víctima, dañando el bien jurídico protegido por la norma penal -principal o accesoriamente-, y cuya reparación se vuelve una necesaria consecuencia de su deterioro, a fin de restituir al agraviado en su derecho, ya sea a manera de indemnización o bien como una forma de procurar la superación del mal causado.

\section{B. Repercusiones del daño moral en niñas, niños y adolescentes víctimas de delitos sexuales}

Si bien el daño moral puede estar asociado con delitos que no necesariamente cuenten con una connotación sexual, como por ejemplo en los delitos de lesiones u homicidio, violencia familiar o cuando los propios adolescentes son instrumentalizados para cometer actos ilícitos, etcétera, válidamente puede afirmarse que todos los delitos de connotación sexual tienen en sí un daño moral aparejado a su ejecución, cuya repercusión irá variando dependiendo de las circunstancias de la comisión del hecho delictivo y de las circunstancias personales de la víctima.

También es innegable que el daño moral, causado en una víctima de un delito de carácter sexual, tiene una mayor afectación cuando es cometido en contra de niñas, niños y adolescentes, pues tal sector presenta una condición biológica distinta a la de los adultos, ya que se encuentran desarrollándose física, psicológica y moralmente, lo cual implica una serie de características e indicadores diferenciales del abuso sexual de acuerdo con la etapa de desarrollo en que se hallen. Además, socialmente, las niñas, niños y adolescentes viven una condición legal distinta, puesto que en la mayoría de los países su concepción como sujetos de derechos es reciente (Barudy, 1999).

Aunado a ello debe considerarse que, entre otras cosas, se afecta el libre desarrollo de la personalidad, así como su sano desarrollo psicosexual, lo que apareja consecuencias que, en caso de no ser atendidas, se irán agravando al paso del tiempo, conforme a la distorsión en la esfera moral de la víctima.

Consideremos en ese sentido, y para entender las repercusiones del daño moral causado, la afirmación de lo que comprende el derecho al libre desarrollo de la personalidad, que proporciona el Pleno de la Suprema Corte de Justicia de la Nación en México, mediante la tesis aislada número P. LXVI/2009, relativa a la Novena Época, que se transcribe:

DERECHO AL LIBRE DESARROLLO DE LA PERSONALIDAD. ASPECTOS QUE COMPRENDE. De la dignidad humana, como derecho fundamental superior reconocido por el orden jurídico mexicano, deriva, entre otros derechos personalísimos, el de todo individuo a elegir en forma libre y autónoma su proyecto de vida. Así, acorde a la doctrina y jurisprudencia comparadas, tal derecho es el reconocimiento del Estado sobre la facultad natural de toda persona a ser individualmente como quiere ser, sin coacción ni controles injustificados, con el fin de cumplir las metas u objetivos que se ha fijado, de acuerdo con sus valores, ideas, expectativas, gustos, etcétera. Por tanto, el libre desarrollo de la personalidad comprende, entre otras expresiones, la libertad de contraer matrimonio o no hacerlo; de procrear hijos y cuántos, o bien, decidir no tenerlos; de escoger 
su apariencia personal; su profesión o actividad laboral, así como la libre opción sexual, en tanto que todos estos aspectos son parte de la forma en que una persona desea proyectarse y vivir su vida y que, por tanto, sólo a ella corresponde decidir autónomamente.

En ese sentido, la ineficacia de la reparación del daño moral producido en una niña, niño o adolescente, con motivo de la comisión de un delito de índole sexual en su contra, podrá tener una repercusión mayor, como ya se ha afirmado anteriormente, en comparación con los efectos que podría producir en un adulto, pues este último tendrá ya un desarrollo y estatus de realización personal y emocional, que como una base, probablemente le ayude a no desviar sus determinaciones personales con posterioridad a la agresión sexual, lo que no ocurre en un niño, niña o adolescente, que aún comienza un camino de definiciones y determinaciones, que como se señala, deberán realizarse sin coacción ni controles injustificados.

A continuación, para mejor entendimiento, expongo con mayor sustento lo mencionado, no sin antes acotar que no es el objetivo del presente ensayo establecer de manera abundante cuáles son las alteraciones que los delitos de carácter sexual tienen como repercusión en la vida de niñas, niños y adolescentes que han sido víctimas de estos ilícitos, pues ahondar en dicha temática desviaría las intenciones objetivas perseguidas, sin embargo, y como en líneas anteriores mencioné, resulta necesario señalar dichos aspectos negativos en la vida de los agraviados, a fin de enmarcar la importancia y necesidad de una correcta reparación del daño moral.

Por tal motivo, me permito citar el ensayo Secuelas emocionales en víctimas de abuso sexual en la infancia, de los doctores Enrique Echeburúa y Paz de Corral, catedráticos de Psicología Clínica de la Universidad del País Vasco, ${ }^{4}$ quienes refieren dentro del apartado denominado Secuelas emocionales en las víctimas de abuso sexual, entre las consecuencias a corto plazo, que al menos el $80 \%$ de las víctimas sufren consecuencias psicológicas negativas (p. 78), señalando textualmente:

El alcance del impacto psicológico va a depender del grado de culpabilización (sic) del niño por parte de los padres, así como de las estrategias de afrontamiento de que disponga la víctima. En general, las niñas tienden a presentar reacciones ansioso-depresivas; los niños, fracaso escolar y dificultades inespecíficas de socialización, así como comportamientos sexuales agresivos.

Respecto a la edad, los niños muy pequeños (en la etapa de preescolar), al contar con un repertorio limitado de recursos psicológicos, pueden mostrar estrategias de negación de lo ocurrido. En los niños un poco mayores (en la etapa escolar) son más frecuentes los sentimientos de culpa y de vergüenza ante el suceso. El abuso sexual presenta una especial gravedad en la adolescencia porque el padre puede intentar el coito, existe un riesgo real de

Aclarando que en dicho ensayo se trata el abuso sexual desde un punto de vista clínico, más genérico que el legal, alusivo a cualquier conducta sexual mantenida entre un adulto y un menor, o entre un menor y otro, y no a la definición que en estricto sentido refiere la teoría penal. 
embarazo y la adolescente toma conciencia del alcance de la relación incestuosa. No son por ello infrecuentes en la víctima conductas como huidas de casa, consumo abusivo de alcohol y drogas, promiscuidad sexual e incluso intentos de suicidio (2006, pp. 78 y 79 ).

Asimismo, dentro de sus conclusiones mencionan lo siguiente:

Las consecuencias de la victimización a corto plazo son, en general, devastadoras para el funcionamiento psicológico de la víctima, sobre todo cuando el agresor es un miembro de la misma familia y cuando se ha producido una violación. Las consecuencias a largo plazo son más inciertas, si bien hay una cierta correlación entre el abuso sexual sufrido en la infancia y la aparición de alteraciones emocionales o de comportamientos sexuales inadaptados en la vida adulta. No deja de ser significativo que un $25 \%$ de los niños abusados sexualmente se conviertan ellos mismos en abusadores cuando llegan a ser adultos. El papel de los factores amortiguadores -familia, relaciones sociales, autoestima, etc.- en la reducción del impacto psicológico parece sumamente importante, pero está aún por esclarecer (Echeburúa y de Corral, 2006, pp. 81 y 82).

No hay que perder de vista que el $74 \%$ de las víctimas de abuso sexual en México son menores de 14 años, y el $81 \%$ de este total son niñas (Torres, 2012, s. p.).

En el caso de las niñas y adolescentes que sufren algún tipo de violencia sexual las consecuencias pueden ser mayores, pues en ocasiones al ser víctimas de violación viven embarazos no deseados, lo que acarrea como resultado que tengan que dejar sus estudios y cambiar sus condiciones personales y sociales para convertirse en madres solteras, en cuyos brazos se deja a un recién nacido, también en estado de vulnerabilidad, aparejando un futuro desolador tanto para la madre como para su hijo.

Es decir, un futuro sin una reparación del daño moral correctamente aplicada, podrá tener consecuencias negativas de gran relevancia en la vida y el desarrollo personal y social de la víctima. Es por ello que, como he mencionado anteriormente, la atención eficaz y eficiente de las víctimas de delitos sexuales, sobretodo tratándose de niñas, niños y adolescentes, resulta de vital importancia ante las severas afectaciones que una desatención pudiera generar tanto en el entorno personal como social; por ello la vigilancia de la aplicación de la reparación del daño moral, en favor de las víctimas, viene a ser un derecho tan importante como lo es en sí la condena a tal pena pública.

\section{NIÑAS, NIÑOS Y ADOLESCENTES. SUS DERECHOS COMO VÍCTIMAS DEL DELITO}

\section{A. Fundamentos de los derechos de niñas, niños y adolescentes víctimas de delitos sexuales}

Sentado lo anterior, y habiendo enfatizado brevemente las repercusiones derivadas de la comisión de un delito de carácter sexual en contra de niñas, niños o adolescentes, estimo procedente establecer los derechos de este sector 
social vulnerable, surgidos a partir de la comisión del delito sexual en su contra, y que son de observancia obligatoria para el Estado, pues de esta forma resultará ilustrativo el fundamento y motivo de la exposición del problema abordado, así como la búsqueda de las soluciones que, en los tres órdenes de gobierno, pudieran tomarse.

Es claro que todo Estado democrático moderno tiene como base primordial, dotar a todos sus integrantes de las garantías máximas que la Ley Suprema proporciona a cada individuo para la protección de sus derechos fundamentales, igualmente contenidos en la propia Carta Magna y en los instrumentos internacionales; de tal suerte que, para demostrar la posibilidad, validez y congruencia de mis pretensiones, es necesario apreciar el fundamento constitucional como principio del marco legal, pues de ahí nace lo que se conoce como el Estado constitucional de derecho, y partiendo de tal supremacía, considerar los tratados internacionales, así como la legislación secundaria vigente.

\section{B. Marco legal nacional e internacional}

En el marco penal, al establecerse la operatividad de la igualdad procesal de las partes en un proceso de esa índole, desde antes de la reforma del 18 de junio de 2008 (en materia del sistema penal acusatorio) se consideraban ya en el artículo 20 constitucional una serie de prerrogativas tanto para el inculpado como para la víctima, divididas en sus dos apartados -A y B-. Como parte de la búsqueda de esa igualdad procesal, en el año 2000 se incorporaron al parágrafo constitucional en cita diversos de- rechos a favor de la víctima u ofendido, como por ejemplo, la palabra ofendido, el derecho a ser informado del proceso penal y a tener asesoría jurídica, el derecho a ofrecer pruebas tanto en la etapa de averiguación previa como en el proceso, el derecho a recibir atención médica y psicológica de urgencia, el derecho de la infancia a no carearse con el inculpado cuando se trate de delitos de violación o secuestro, y las medidas de providencia y auxilio según las leyes secundarias.

Asimismo, dentro del artículo citado, se establece en la fracción IV el derecho de la víctima a que se le repare el daño, imponiéndose la obligación de que, en los casos que sea procedente, el Ministerio Público solicite la reparación del daño, y la obligación del juez de no absolver de dicha sanción en caso de emitir una sentencia condenatoria; en la misma fracción, en el segundo párrafo, se establece: “la ley fijará procedimientos ágiles para ejecutar las sentencias en materia de reparación del daño".

Ahora bien, en el texto del artículo 20, posterior a la reforma señalada en el párrafo que antecede, se estableció en el inciso A, denominado De los principios generales, en la fracción I, como uno de los principios rectores del proceso penal "que los daños causados por el delito se reparen"; se conservó en el apartado: De los derechos de la víctima o del ofendido, el derecho a recibir desde la comisión del delito, atención médica y psicológica de urgencia, así como el derecho a que se le repare el daño, prácticamente en los mismos términos que el texto no reformado, pero incluyéndose el derecho a que 
la víctima o el ofendido puedan solicitar directamente la reparación del daño. En la fracción VII se incluyó la posibilidad de la víctima de impugnar, entre otras resoluciones, aquellas donde no esté satisfecha la reparación del daño. Aunado a lo anterior, en virtud de la ponderación entre un derecho del imputado frente a la afectación que su desahogo causaba al agraviado, en la reforma de referencia se suprimió la figura procesal de careos, en la que se confrontaba al imputado con la víctima, con la finalidad de que discutieran respecto a las contradicciones que existieran en sus dichos, o bien para que el imputado interrogara a la víctima.

En ese sentido, y no perdiendo la horizontalidad constitucional, cabe destacar el artículo $1^{\circ}$ a partir de la reforma de junio de 2011, en el que se estableció de manera literal:

En los Estados Unidos Mexicanos todas las personas gozarán de los derechos humanos reconocidos en esta Constitución y en los tratados internacionales de los que el Estado Mexicano sea parte, así como de las garantías para su protección, cuyo ejercicio no podrá restringirse ni suspenderse, salvo en los casos y bajo las condiciones que esta Constitución establece. Las normas relativas a los derechos humanos se interpretarán de conformidad con esta Constitución y con los tratados internacionales de la materia favoreciendo en todo tiempo a las personas la protección más amplia. Todas las autoridades, en el ámbito de sus competencias, tienen la obligación de promover, respetar, proteger y garantizar los derechos humanos de conformidad con los principios de universalidad, interdependencia, indivisibilidad y progresividad. En consecuencia, el Estado deberá prevenir, investigar, sancionar y reparar las violaciones a los derechos humanos, en los términos que establezca la ley. Está prohibida la esclavitud en los Estados Unidos Mexicanos. Los esclavos del extranjero que entren al territorio nacional alcanzarán, por este solo hecho, su libertad y la protección de las leyes. Queda prohibida toda discriminación motivada por origen étnico o nacional, el género, la edad, las discapacidades, la condición social, las condiciones de salud, la religión, las opiniones, las preferencias sexuales, el estado civil o cualquier otra que atente contra la dignidad humana y tenga por objeto anular o menoscabar los derechos y libertades de las personas.

Si bien el artículo $1^{\circ}$ no es innovador en lo relativo a la jerarquía de los tratados internacionales, pues estos ya estaban contemplados en la Carta Magna (artículo 133), sí conlleva un cambio en el paradigma de aplicación constitucional y convencional en el mandato supremo dirigido a todas las autoridades, para que observen en su actuar el respeto a los derechos humanos contenidos en la Constitución, así como en los tratados internacionales de que México forme parte, además se impone la interpretación de las normas de derechos humanos de conformidad con la Constitución y los tratados, favoreciendo en todo tiempo la protección más amplia a las personas. Lo último señalado, representado por los principios de interpretación conforme y pro persona.

En cuanto a los derechos de la niñez, el artículo 4 Constitucional, en vigor, ${ }^{5}$ establece que

$5 \quad$ A partir de la Reforma del 12 de octubre de 2011. 
en todas las decisiones y actuaciones del Estado se velará y cumplirá con el principio del interés superior de la niñez, garantizando de manera plena sus derechos. Los niños y las niñas tienen derecho a la satisfacción de sus necesidades de alimentación, salud, educación y sano esparcimiento para su desarrollo integral. Este principio deberá guiar el diseño, ejecución, seguimiento y evaluación de las políticas públicas.

Asimismo, en cuanto a las facultades correspondientes al Congreso de la Unión, se establece en el artículo 73 fracción XXIX-P, la de

expedir leyes que establezcan la concurrencia de la Federación, los Estados, el Distrito Federal y los Municipios, en el ámbito de sus respectivas competencias, en materia de derechos de niñas, niños y adolescentes, velando en todo momento por el interés superior de los mismos y cumpliendo con los tratados internacionales de la materia, de los que México sea parte.

Respecto a la expresión principio del interés superior de la niñez, la Primera Sala de la Suprema Corte de Justicia de la Nación estableció mediante la tesis 1a. CXLI/2007, relativa a la Novena Época, su concepto, tomando en consideración lo siguiente:

INTERÉS SUPERIOR DEL NIÑO. SU CONCEPTO. En términos de los artículos 4o. de la Constitución Política de los Estados Unidos Mexicanos; 3 de la Convención sobre los Derechos del Niño (ratificada por México y publicada en el Diario Oficial de la Federación el 25 de enero de 1991); y 3, 4, 6 y 7 de la Ley para la Protección de los Derechos de Niñas, Niños y Adolescentes, los tribunales deben atender primordialmente al interés su- perior del niño, en todas las medidas que tomen concernientes a éstos, concepto interpretado por la Corte Interamericana de Derechos Humanos (cuya competencia aceptó el Estado Mexicano el 16 de diciembre de 1998 al ratificar la Convención Interamericana de Derechos Humanos) de la siguiente manera: "la expresión 'interés superior del niño' ... implica que el desarrollo de éste y el ejercicio pleno de sus derechos deben ser considerados como criterios rectores para la elaboración de normas y la aplicación de éstas en todos los órdenes relativos a la vida del niño (p. 265).

A nivel internacional, debe considerarse el artículo 3 de la Convención sobre los Derechos del Niño, ${ }^{6}$ citado en la tesis antes transcrita, en sus apartados 1 y 2 , que disponen que "en todas las medidas concernientes a los niños que tomen las instituciones públicas o privadas de bienestar social, los tribunales, las autoridades administrativas o los órganos legislativos, una consideración primordial a que se atenderá será el interés superior del niño", y que: “los Estados Partes se comprometen a asegurar al niño la protección y el cuidado que sean necesarios para su bienestar, teniendo en cuenta los derechos y deberes de sus padres, tutores $u$ otras personas responsables de él ante la ley y, con ese fin, tomarán todas las medidas legislativas y administrativas adecuadas".

De igual forma cobran relevancia los puntos 1 y 2 del artículo 19 de la propia Convención, que refieren que:

6 Firmada por el Estado Mexicano el día 26 de enero de 1990, publicada por Decreto Presidencial en el Diario Oficial de la Federación el 28 de noviembre del mismo año. 
los Estados Partes adoptarán todas las medidas legislativas, administrativas, sociales $y$ educativas apropiadas para proteger al niño contra toda forma de perjuicio o abuso físico o mental, descuido o trato negligente, malos tratos o explotación, incluido el abuso sexual, mientras el niño se encuentre bajo la custodia de los padres, de un representante legal o de cualquier otra persona que lo tenga a su cargo, (énfasis agregado)

y que

esas medidas de protección deberían comprender, según corresponda, procedimientos eficaces para el establecimiento de programas sociales con objeto de proporcionar la asistencia necesaria al niño y a quienes cuidan de él, así como para otras formas de prevención y para la identificación, notificación, remisión a una institución, investigación, tratamiento y observación ulterior de los casos antes descritos de malos tratos al niño y, según corresponda, la intervención judicial. (Énfasis agregado).

El artículo 34 expresa que “los Estados Partes se comprometen a proteger al niño contra todas las formas de explotación y abuso sexuales...".

Por su parte, el artículo 39 establece que:

los Estados Partes adoptarán todas las medidas apropiadas para promover la recuperación física y psicológica y la reintegración social de todo niño víctima de: cualquier forma de abandono, explotación o abuso; tortura u otra forma de tratos o penas crueles, inhumanos o degradantes; o conflictos armados. Esa recuperación y reintegración se llevarán a cabo en un ambiente que fomente la salud, el respeto de sí mismo y la dignidad del niño.
Asimismo, cobra relevancia el Pacto Internacional de Derechos Civiles y Políticos, ${ }^{7}$ pues en su artículo 24.1 establece: "Todo niño tiene derecho, sin discriminación alguna por motivos de raza, color, sexo, idioma, religión, origen nacional o social, posición económica o nacimiento, a las medidas de protección que su condición de menor requiere, tanto por parte de su familia como de la sociedad y del Estado".

A nivel continental, la Convención Americana de Derechos Humanos (Pacto de San José), ${ }^{8}$ en el artículo 19 dispone: "Todo niño tiene derecho a las medidas de protección que su condición de menor requieren por parte de su familia, de la sociedad y del Estado".

En cuanto al Código Penal Federal, el artículo 6, último párrafo dispone: “En caso de delitos cometidos en contra de niñas, niños y adolescentes siempre se procurará el interés superior de la infancia que debe prevalecer en toda aplicación de ley".

La Ley para la Protección de Derechos de Niñas, Niños y Adolescentes, publicada en el Diario Oficial de la Federación el 29 de mayo de 2000, y la última reforma publicada el 19 de agosto de 2010, desde luego contiene disposiciones de carácter obligatorio, de las cuales cito los siguientes artículos que considero de relevante interés para la temática expuesta:

$7 \quad$ Publicado en el Diario Oficial de la Federación el 20 de mayo de 1981.

$8 \quad$ Publicada en el Diario Oficial de la Federación el 7 de mayo de 1981. 
Artículo 1. La presente ley se fundamenta en el párrafo sexto del artículo 4o. de la Constitución Política de los Estados Unidos Mexicanos, sus disposiciones son de orden público, interés social y de observancia general en toda la República Mexicana y tiene por objeto garantizar a niñas, niños y adolescentes la tutela y el respeto de los derechos fundamentales reconocidos en la Constitución.

Artículo 3. La protección de los derechos de niñas, niños y adolescentes, tiene como objetivo asegurarles un desarrollo pleno e integral, lo que implica la oportunidad de formarse física, mental, emocional, social y moralmente en condiciones de igualdad.

Son principios rectores de la protección de los derechos de niñas, niños y adolescentes:
A. El del interés superior de la infancia.

B. El de la no-discriminación por ninguna razón, ni circunstancia.

C. El de igualdad sin distinción de raza, edad, sexo, religión, idioma o lengua, opinión política o de cualquier otra índole, origen étnico, nacional o social, posición económica, discapacidad, circunstancias de nacimiento o cualquiera otra condición suya o de sus ascendientes, tutores o representantes legales.

D.El de vivir en familia, como espacio primordial de desarrollo.

E. El de tener una vida libre de violencia.

F. El de corresponsabilidad de los miembros de la familia, Estado y sociedad.
G. El de la tutela plena e igualitaria de los derechos humanos y de las garantías constitucionales.

Artículo 4. De conformidad con el principio del interés superior de la infancia, las normas aplicables a niñas, niños y adolescentes, se entenderán dirigidas a procurarles, primordialmente, los cuidados y la asistencia que requieren para lograr un crecimiento y un desarrollo plenos dentro de un ambiente de bienestar familiar y social...

Artículo 5. La Federación, el Distrito Federal, los estados y los municipios, procurarán implementar los mecanismos necesarios para impulsar una cultura de protección de los derechos de la infancia, basada en el contenido de la Convención Sobre los Derechos del Niño y tratados que sobre el tema apruebe el Senado de la República.

Artículo 7. Corresponde a las autoridades o instancias federales, del Distrito Federal, estatales y municipales en el ámbito de sus atribuciones, la de asegurar a niñas, niños y adolescentes la protección y el ejercicio de sus derechos y la toma de medidas necesarias para su bienestar tomando en cuenta los derechos y deberes de sus madres, padres, y demás ascendientes, tutores y custodios, $u$ otras personas que sean responsables de los mismos. De igual manera y sin prejuicio de lo anterior, es deber y obligación de la comunidad a la que pertenecen y, en general de todos los integrantes de la sociedad, el respeto y el auxilio en el ejercicio de sus derechos.

El Gobierno Federal promoverá la adopción de un Programa Nacional Para la Atención de los Derechos de la Infancia y Adolescencia, en el 
que se involucre la participación de las entidades federativas y municipios, en el ámbito de sus respectivas competencias, así como del sector privado y social, para la instrumentación de políticas y estrategias que contribuyan al cumplimiento de la presente ley y garantice el mejoramiento de la condición social de niñas, niños y adolescentes.

Artículo 13. A fin de garantizar el cumplimiento de los derechos establecidos en este capítulo, las leyes federales, del Distrito Federal y de las entidades federativas podrán disponer lo necesario para que se cumplan en todo el país:

A. Las obligaciones de ascendientes o tutores, o de cualquier persona que tenga a su cargo el cuidado de una niña, de un niño, o de un o una adolescente de protegerlo contra toda forma de abuso; tratarlo con respeto a su dignidad y a sus derechos; cuidarlo, atenderlo y orientarlo a fin de que conozca sus derechos, aprenda a defenderlos y a respetar los de las otras personas.

B. Para que el Estado, en los ámbitos federal, estatal y municipal pueda intervenir, con todos los medios legales necesarios, para evitar que se generen violaciones, particulares o generales del derecho de protección de niñas, niños y adolescentes. Especialmente se proveerá lo necesario para evitar que salgan del país sin que medie la autorización de sus padres, tutores o de un juez competente...

Artículo 19. Niñas, niños y adolescentes tienen derecho a vivir en condiciones que permitan su crecimiento sano y armonioso, tanto físico como mental, material, espiritual, moral y social.

Artículo 21. Niñas, niños y adolescentes tienen el derecho a ser protegidos contra actos $u$ omisiones que puedan afectar su salud física o mental, su normal desarrollo o su derecho a la educación en los términos establecidos en el artículo 3o. constitucional. Las normas establecerán las formas de prever y evitar estas conductas. Enunciativamente, se les protegerá cuando se vean afectados por:

A. El descuido, la negligencia, el abandono, el abuso emocional, físico y sexual...

Artículo 48. Para una mejor defensa y protección de los derechos de niñas, niños y adolescentes a nivel nacional, las instituciones que la Federación, el Distrito Federal, los estados y municipios establezcan, en el ámbito de sus respectivas competencias, contarán con el personal capacitado y serán instancias especializadas con funciones de autoridad para la efectiva procuración del respeto de tales derechos.

Aunado a ello, cabe mencionar que las Directrices sobre la Justicia para los Niños Víctimas y Testigos de Delitos, documento emitido por la Oficina Internacional de los Derechos del Niño, señalan en el punto número 9 que los niños deben recibir, siempre que sea posible, reparación a fin de lograr el pleno resarcimiento, reintegración y recuperación, y que los procedimientos para obtener y asegurar la reparación deben ser de fácil acceso y adaptados a los niños.

Con la exposición de los dispositivos legales antes efectuada, ya contamos con un panorama legal suficiente y basto, que permite justificar el presente trabajo en apego a las normas aplicables, con base en las obligaciones que el Estado tiene como garante de los derechos humanos de niñas, niños y adolescentes, mismas obliga- 
ciones que se derivan de la normatividad, y que en adelante se exponen como una abstracción de lo ya citado.

\section{EL ESTADO COMO GARANTE DE LA CORRECTA APLICACIÓN DE LA REPARACIÓN DEL DAÑO MORAL. SU JUSTIFICACIÓN}

\section{A. De las obligaciones del Estado}

Una vez establecido el marco legal, y de una interpretación sistemática del contenido constitucional, los tratados y pactos internacionales en cita, así como la legislación nacional relacionada con la materia, puede establecerse lo siguiente:

- Que el Estado, en sus diferentes órdenes de gobierno, tiene la obligación de velar por la promoción, respeto, protección y garantía de los derechos humanos contenidos en la Constitución y en los tratados internacionales en la materia, de los que México forme parte;

- Que el Estado tiene la obligación, en todas sus decisiones y actuaciones (judiciales, administrativas, legislativas, etcétera), de velar y cumplir con el principio de interés superior de la niñez, garantizando plenamente sus derechos (entre ellos el sano esparcimiento para su desarrollo integral), teniendo en cuenta la vulnerabilidad de dicho sector social.

- Que el derecho a la reparación del daño derivado de la comisión de un delito -incluyendo desde luego el daño moral-, es un derecho humano reconocido por la Constitución y por los tratados internacionales.

- Que el Estado está obligado a proteger los derechos de niñas, niños y adolescentes, teniendo como objetivo asegurarles un desarrollo pleno e integral, lo que implica la oportunidad de formarse física, mental, emocional, social y moralmente en condiciones de igualdad.

- Que el Estado tiene la obligación de adoptar todas las medidas legislativas, administrativas, sociales y educativas apropiadas para proteger al niño contra toda forma de perjuicio o abuso físico o mental, descuido o trato negligente, malos tratos o explotación, incluido el abuso sexual.

- Que dichas medidas estatales deberán comprender, según corresponda, procedimientos eficaces para el establecimiento de programas sociales con el objeto de proporcionar la asistencia necesaria al niño y a quienes cuidan de él, así como para otras formas de prevención y para la identificación, notificación, remisión a una institución, investigación, tratamiento y observación ulterior de los casos antes descritos de malos tratos al niño y, según corresponda, la intervención judicial.

- Que el Estado está obligado, además, a adoptar todas las medidas apropiadas para promover la recuperación física y psicológica y la reintegración social de todo niño víctima de: cualquier forma de abandono, explotación o abuso; tortura u otra forma de tratos crueles, 
inhumanos o degradantes; o conflictos armados, misma recuperación y reintegración que se llevará a cabo en un ambiente que fomente la salud, el respeto de sí mismo y la dignidad del niño.

- Que el Estado, en sus diferentes instancias (federal, estatal, municipal), tiene la obligación de asegurar a niñas, niños y adolescentes la protección y el ejercicio de sus derechos y la toma de medidas necesarias para su bienestar teniendo en cuenta los derechos y deberes de sus madres, padres y demás ascendientes, tutores y custodios, u otras personas que sean responsables de estos.

- Que el Estado, en sus diferentes instancias, deberá disponer lo necesario a fin de que se cumplan las obligaciones de ascendientes $o$ tutores, o de cualquier persona que tenga a su cargo el cuidado de una niña, de un niño, o de un o una adolescente de protegerlo contra toda forma de abuso; tratarlo con respeto a su dignidad y a sus derechos; cuidarlo, atenderlo y orientarlo a fin de que conozca sus derechos, aprenda a defenderlos y a respetar los de las otras personas. Así como para que el Estado, en los ámbitos federal, estatal y municipal pueda intervenir, con todos los medios legales necesarios, para evitar que se generen violaciones, particulares o generales del derecho de protección de niñas, niños y adolescentes.

- Que el Estado tiene la obligación de proteger a niñas, niños y adolescentes contra actos $u$ omisiones que puedan afectar su salud física o mental, su normal desarrollo o su derecho a la educación en los términos establecidos en el artículo 3o. constitucional.

- Que el Estado tiene la obligación de emitir normas en las que se establecerán las formas de prever y evitar estas conductas. Siendo que niñas, niños y adolescentes, deberán ser protegidos, entre otras cosas contra el abuso sexual.

De todo lo antes precisado, considerando que las obligaciones que se han reseñado son carga del Estado, a continuación expongo de manera concreta los puntos que establecen la problemática hasta ahora abordada:

- Que las niñas, niños y adolescentes, que han sido víctimas de la comisión de un delito de carácter sexual, tienen derecho a la reparación del daño moral, lo que representa un derecho humano reconocido en la Constitución y los tratados internacionales de los que México es parte.

- Que la reparación del daño moral deberá tener como finalidad la indemnización del daño moral causado, incluyendo la atención médica y psicológica, los servicios sociales y de rehabilitación o tratamientos curativos necesarios para la recuperación de la salud, que hubiere requerido o requiera la víctima, como consecuencia del delito, además de los tratamientos psicoterapéuticos que sean necesarios.

- Lo anterior a fin de lograr la restauración de la afectación que el niño, niña o adolescente haya sufrido en sus sentimientos, afectos, 
creencias, decoro, honor, reputación, vida privada, configuración y aspectos físicos, o bien en la consideración que de sí mismos tienen los demás. Así como para restituir a la víctima en el libre desarrollo de la personalidad y en su sano desarrollo psicosexual.

- Que en los procesos del orden penal, cuando las niñas, niños y adolescentes conserven esa calidad, deberán ser representados por un legítimo representante.

- Que al encontrarse sus derechos representados por una tercera persona, se corre el riesgo de que los recursos correspondientes a la reparación del daño moral no se utilicen de manera idónea con esa finalidad.

- Que ante tal riesgo podría no darse una verdadera justicia, al no conseguirse la restitución de la afectación sufrida por el niño, niña o adolescente víctima del delito.

Así pues, de la confrontación de dicha problemática con las obligaciones del Estado, de manera silogística puede concluirse que el Estado deberá ser el garante de la promoción, respeto, conservación y garantía de los derechos humanos de niñas, niños y adolescentes, entre ellos el derecho a la reparación del daño moral derivado de la comisión de un delito de carácter sexual cometido en su contra, vigilando que los bienes obtenidos como resultado de una condena a esa pena pública sean correctamente aplicados en favor de niñas, niños o adolescentes víctimas del delito, a fin de eliminar los obstáculos que permitan el acceso de estos a una impartición de justicia integral, sin que ello invada la esfera de derechos que los representantes legales de las víctimas tienen en cuanto a velar por su sano desarrollo personal, emocional, psicológico, social, educacional, físico, sexual, etcétera.

En el apartado de conclusiones puntualizaré algunas de las políticas que podrían tomarse, a fin de lograr, fáctica y jurídicamente, lo expuesto en el párrafo que antecede.

\section{El derecho a recibir atención con independencia al derecho a la eficaz aplicación de la reparación del daño moral}

Antes de concluir, quisiera resaltar que no debe confundirse la obligación constitucional del Estado de proporcionarle a las niñas, niños y adolescentes los servicios de atención médica y psicológica que requieran - de urgencia- por la comisión de un ilícito, con lo que he señalado como la obligación del Estado de velar porque los recursos derivados de la condena a la reparación del daño moral otorgada por el sentenciado, sean eficazmente empleados para los fines que se precisen, pues el primero constituye una política pública genérica como derecho fundamental, cuyo cumplimiento está en manos del Estado con total independencia de terceros, es decir, es una relación directa entre el Estado y la víctima, tal vez con fines de igual sentido que los de una reparación del daño moral, pero un tanto difusos en cuando a los casos particulares, mientras que el segundo se concretiza a cada caso específico, y en él intervienen múltiples 
factores, como la fijación de la cuantía económica que hagan los tribunales y la representación con la que cuente la víctima del delito.

Su diferencia estriba básicamente en que el primero es un derecho a una prestación, mientras que el segundo es una indemnización o pago restitutorio al que deberá condenarse a quien se declare culpable; además de ello, para que surta vitalidad el primero, no es necesario que se emita una sentencia de culpabilidad, mientras que para que exista el segundo la sentencia es un elemento indispensable.

El primero es un servicio de urgencia, que aplica el Estado a través de las diferentes unidades de atención a víctimas con las que cuentan las procuradurías o fiscalías generales, federal y de las entidades federativas, entre otras instituciones, por lo que en ocasiones el tratamiento no es el correcto, pues al ser un servicio de urgencia no cuenta con el seguimiento y personalización necesarios para una adecuada atención, aunado a la falta de especialización y sensibilización que podría generar una victimización secundaria o revictimización; el segundo puede enfocarse a una terapia específica y especializada, atendida según las circunstancias del caso por profesionales ajenos a las instituciones públicas.

A nivel internacional, federal, así como en algunas entidades federativas se prevé ${ }^{9}$ y en otras está en vías de desarrollo, la creación de un fideicomiso de ayuda para las víctimas de delito o fondos generales de reparaciones a las vícti- mas del delito, los cuales son o serán operados por las procuradurías o fiscalías de los estados, y tienen como finalidad aportar recursos que resulten necesarios a las víctimas del delito en materia de asesoría jurídica, asistencia médica y psicológica y la reparación del daño. Sin embargo, no pasa desapercibido para mí que estos son efectivos siempre y cuando exista sentencia firme en la que se condene al pago de la reparación del daño a favor de la víctima y el sentenciado no pueda pagar o garantizar su pago, ello con independencia de que el ministerio público se subrogue en los derechos de la víctima reconocidos en el proceso penal, que se deriven del pago de reparación de los daños que realice conforme a esta Ley, y pueda hacerlo exigible al sentenciado; sin embargo, la obligación del Estado debe hacerse más extensiva, en aras de contar con la posibilidad de vigilar que la reparación del daño moral haya sido aplicada en su totalidad para lo que fue determinada, ello en los casos en que el delito afectare a niñas, niños y adolescentes.

Por lo tanto, es factible considerar que ambas son obligaciones completamente diferentes del Estado, cuyo cumplimiento es independiente, sin que una condicione a la otra, ni mucho menos la segunda sustituya a la primera, pues la atención de urgencia se dará a partir de la comisión del delito, mientras que la aplicación de la reparación del daño moral vendrá como consecuencia de la imposición de una pena mediante una sentencia condenatoria.

\section{CONCLUSIONES}

9 Entre ellas Chihuahua, Baja California y el Distrito Federal. 
Una vez sentado lo anterior, concluiré con las consideraciones que a mi parecer son de utilidad para combatir la problemática planteada durante el desarrollo del presente ensayo, con la esperanza de haber sido preciso en los conceptos y claro en las ideas que pretendí transmitir, y que de ser así, como señalé en la introducción, pueda despertar en otros una preocupación accesoria al combate contra los abusos sexuales cometidos en contra de niñas, niños y adolescentes, pues la temática nacional al respecto únicamente se ha dirigido a la forma de erradicar la comisión de tales ilícitos y la manera de sancionar a los responsables, pero no al futuro de las víctimas cuando sus derechos se encuentran en manos de terceros, que incluso podrán tener algún tipo de parentesco con el agresor, lo que puede representar un factor que imposibilite lograr una reparación del daño integral, y como dije, finalmente acarreará una justicia a medias.

Procediendo con lo referido, debo precisar que de conformidad con el reformado artículo 21 de la Constitución Política de los Estados Unidos Mexicanos “La imposición de las penas, su modificación y duración son propias y exclusivas de la autoridad judicial". De ahí, y en atención a las diversas reformas en materia penal, que naciera la figura del juez de ejecución de sanciones en materia penal, aclarando al respecto que en los artículos transitorios de la reforma penal de 2008 se concedió una vacatio legis tanto para el fuero común como el federal de un año para la implementación del nuevo modelo de reinserción social, por lo que desde el año 2009 todas las entidades federativas y el fuero federal deben contar con jueces de ejecu- ción de sanciones; por lo tanto, en materia de sentencia, la ejecución corresponde al juez de ejecución, cuya función será velar por el correcto cumplimiento de las sanciones impuestas, la búsqueda de la reinserción de los sentenciados, la vigilancia de un ambiente propicio y la concesión de beneficios a los sentenciados con relación a la pena, además de la modificación de esta e incluso sobre los casos de prescripción. ${ }^{10}$

De tal forma que cuando una persona es sentenciada, y dentro de la condena se encuentra la reparación del daño moral, será ante dicha autoridad que deberá cumplir tal pena, a fin de que el juez de ejecución a su vez realice la entrega a la parte agraviada, para los efectos correspondientes, con lo cual se da por cumplida la pena impuesta; por lo tanto, será a partir de dicho momento cuando deberá accionarse la actuación del Estado en sus diferentes órdenes (legislativo, ejecutivo y judicial), a fin de velar por la correcta aplicación de los recursos derivados de la reparación del daño moral.

En el caso de niñas, niños o adolescentes, los recursos económicos derivados del cumplimiento del pago de la reparación del daño moral, por motivo de representación, serán entregados a su legítimo representante, comúnmente a la

10 Con la precisión de que antes de la reforma de 2008, la ejecución de las sanciones penales ya correspondía a las distintas instancias del poder judicial, pero se encontraban limitadas dado que el otorgamiento de beneficios preliberacionales era una facultad del poder ejecutivo, y técnicamente tales beneficios implicaban una modificación de la sentencia. El cambio radica en ello precisamente, por eso la Constitución ahora refiere a "su modificación". Así, se crea esta figura de nuevos jueces especializados a fin de despresurizar a los jueces del proceso penal, entre otros propósitos, y preservar para la función jurisdiccional no solo la imposición de la pena, sino también su eventual modificación ante el otorgamiento de un beneficio de ley. 
En ese sentido las propuestas serían las siguientes:

- En la audiencia de entrega correspondiente, hacer saber a la persona que recibe los recursos económicos cuáles son las finalidades de estos, y que bajo protesta de decir verdad la parte que recibe se comprometa a destinar dichos recursos para la reparación del daño moral del niño, niña o adolescente directamente afectado.

- Que exista una comunicación entre la autoridad judicial de ejecución y las dependencias encargadas de velar por los derechos de niñas, niños y adolescentes, como el Sistema Nacional para el Desarrollo Integral de la Familia (DIF) o las diversas procuradurías de la Defensa del Menor y la Familia en los estados, con la finalidad de que:

- Estén enteradas de la entrega de los recursos para la reparación del daño moral al legítimo representante del niño, niña o adolescente agraviado, y las especificaciones necesarias.

- Puedan mantener una vigilancia y seguimiento que garantice que los recursos son efectivamente destinados para tal efecto, así como valorar el estado psicológico y personal de la víctima.

- El juez de ejecución deberá disponer al representante legal del niño, niña o adolescente, que comparezca ante la institución corres-
- Facultar a las autoridades para realizar las acciones descritas, ya sea mediante la creación de ordenamientos legales o modificación de los existentes, iniciando con una adhesión al artículo 20 constitucional apartado C, mediante la cual se prevea la obligación del Estado de velar porque los recursos derivados del cumplimiento de la reparación del daño moral, cuando se trate de niñas, niños y adolescentes, sean eficazmente aplicados para ese efecto.

- Establecer en dichos instrumentos, de igual forma, sanciones para aquellos representantes legales que incumplan con su obligación, haciendo perseguible de oficio tal delito.

- Disponer de un servicio de asistencia psicológica o terapéutica especializada, adonde puedan ser canalizadas las víctimas de delitos sexuales, cuando sean niñas, niños o adolescentes. Dicho servicio puede ser prestado a través de una institución a la cual podrán acudir los representantes legales de las víctimas, como una opción para el destino de los recursos económicos dispuestos, cuyos costos serán asequibles dependiendo del caso particular. ${ }^{11}$

- Hacer conciencia social respecto a tal derecho, a fin de que niñas, niños y adolescentes

11 Considerando que la recientemente promulgada Ley General de Víctimas establece la creación de una Comisión Ejecutiva de Atención a Víctimas, podría disponerse que esta Comisión cuente con un aparato especializado para la atención de personas menores de dieciocho años de edad que hayan sido víctimas de delitos sexuales. 
lo conozcan y estén en capacidad de hacerlo exigible.

Concluyo con una cita de la ministra Olga Sánchez Cordero de García Villegas, en su participación en el foro El principio del interés superior de la infancia en las resoluciones judiciales, ${ }^{12}$ en la que puntualmente señaló:

El futuro pertenece a los ahora niños y niñas, por lo que todos debemos trabajar para que tengan una vida digna y un desarrollo integral, que les permita llegar a ser ciudadanos y ciudadanas felices, responsables, con necesidad de crecimiento, en una palabra, íntegros.

Por eso, necesitamos que el interés superior de la niñez, consagrado tanto en la Constitución Política de los Estados Unidos Mexicanos, como en los tratados internacionales de los que México es parte, constituya el criterio rector para la elaboración de normas y para la aplicación de éstas, en todos los órdenes relativos a la vida de las y los niños.

\section{Referencias}

Barudy J. (1999). Maltrato infantil. Ecología social: prevención y reparación. Santiago de Chile: Editorial Galdoc.

Código Civil Federal. Diario Oficial de la Federación, 09 de abril de 2012.

12 Organizado por la Comisión de Derechos Humanos del Distrito Federal, el 25 de noviembre de 2011. Disponible en: http://www.scjn.gob. $\mathrm{mx} /$ conocelacorte/ministra/conferencia20111125.pdf
Código Federal de Procedimientos Penales.

Código Penal Federal. Diario Oficial de la Federación, 14 de junio de 2012.

Comisión de Derechos Humanos del Distrito Federal. (25 de noviembre de 2011). El principio del interés superior de la infancia en las resoluciones judiciales. Obtenido de Suprema Corte de Justicia de la Nación: http:// www.scjn.gob.mx/conocelacorte/ministra/ conferencia20111125.pdf

Constitución Política de los Estados Unidos Mexicanos.

Echeburúa Odriozola, E. y de Corral, P. (2006). Secuelas emocionales en víctimas de abuso sexual en la infancia. Cuadernos de Medicina Forense, XII (43-44), 75-82.

Enciclopedia Jurídica OMEBA.

Hernández Pliego, J. A. (2006). Programa de Derecho Procesal Penal. México: Porrúa.

Ley para la Protección de Derechos de Niñas, Niños y Adolescentes. Diario Oficial de la Federación, 29 de mayo de 2000 y 19 de agosto de 2010.

Meza Fonseca, E. (2004). Hacia una Justicia Restaurativa en México. Revista del Instituto de la Judicatura Federal, (18).

Oficina de la Defensoría de los Derechos de la Infancia. (2005). El niño víctima del delito, fundamentos y orientaciones para una refor- 
ma procesal penal. Tomo I. Colección El niño víctima del delito frente al proceso penal. México: ODI.

Oficina Internacional de los Derechos del Niño. (2003). Directrices sobre la Justicia para los Niños Víctimas y Testigos de Delitos. Montreal: Oficina Internacional de los Derechos del Niño.

Organización de las Naciones Unidas. (20 de noviembre de 1989). Convención sobre los Derechos del Niño.

Organización de las Naciones Unidas. (29 de noviembre de 1985). Declaración sobre los Principios Fundamentales de Justicia para las Víctimas de Delitos y del Abuso del Poder.

Organización de las Naciones Unidas. Pacto Internacional de Derechos Civiles y Políticos. Diario Oficial de la Federación, 20 de mayo de 1981.

Organización de los Estados Americanos. Convención Americana de Derechos Humanos, Pacto de San José.
Pérez Duarte y Noroña, A. E. (1985). El daño moral. Boletín Mexicano de Derecho Comparado, (53), 625-638.

Suprema Corte de Justicia de la Nación. [Pleno]. (Diciembre, 2009). Tesis aislada número P. LXVI/2009. Semanario Judicial de la Federación, y su Gaceta. Novena Época. Tomo XXX. Registro n. ${ }^{\circ} 165822$.

Suprema Corte de Justicia de la Nación. (Enero, 2012). Tesis jurisprudencial número I.3o.C. J/71. Semanario Judicial de la Federación, y su Gaceta. Décima Época. Libro IV. Tomo 5.

Suprema Corte de Justicia de la Nación. Primera Sala. (Julio, 2007). Tesis 1a. CXLI/2007. Semanario Judicial de la Federación y su Gaceta. Tomo XXVI.

Torres Ruiz, G. (11 de octubre de 2012). Niñas, mayoría de víctimas de abuso sexual en México. Obtenido de CN Cimacnoticias: http:// cimacnoticias.com.mx/node/61788 